\title{
Effect of Vitamin D Supplementation on Moderate to Severe Bronchial Asthma: Correspondence 2
}

\author{
Ömer Kartal • Ayșe Tuğba Kartal
}

Received: 26 August 2014 / Accepted: 24 December 2014 / Published online: 25 January 2015

(C) Dr. K C Chaudhuri Foundation 2015

To the Editor: We have read with great interest the recent article by Yadav and Mittal [1]. In this excellent study, the authors investigated the therapeutic role of vitamin D in children with moderate to severe bronchial asthma as an adjunct to standard treatment. They concluded that vitamin $D$ has a definite role in the management of moderate to severe persistent bronchial asthma as an adjunct to standard treatment. We appreciate and congratulate the authors for having addressed such an important issue. However, we have some concerns related to the study design and methodology which call into question the validity of their findings.

Firstly, according to the some studies, plasma concentrations of vitamin D may effect the airway response to inhaled corticosteroids and lung function in asthma [2,3]. At all ages, exposure to sunlight, specifically UVB, is believed to provide most of the vitamin D requirements of the human population [4]. Furthermore, the seasonal variation of vitamin D levels in the children are expected because of the changing sunlight exposure [5]. In addition to these, lifestyle, obesity, exposure to cigarette smoke, and inadequate physical activity are substantial for plasma concentrations of vitamin D [2]. However, all of these were not evaluated before the treatment by the authors. Therefore, validity of the findings is suspicious.

Secondly, the population evaluated in the study is too small to generalize to the community.

Ö. Kartal $(\bowtie)$

Department of Pediatrics, Aksaz Military Hospital, 48750 Mugla,

Turkey

e-mail: dr.omerkartal@hotmail.com

A. T. Kartal

Department of Pediatrics, Marmaris State Hospital, 48750 Mugla,

Turkey
Finally, randomized, double-blind, placebo-controlled, large scale studies are needed in asthma populations to evaluate causal relationships between vitamin $\mathrm{D}$ treatment and outcomes and to develop recommendations for treatment.

Conflict of Interest None.

Source of Funding None.

\section{References}

1. Yadav M, Mittal K. Effect of vitamin D supplementation on moderate to severe bronchial asthma. Indian J Pediatr. 2014;81:650-4.

2. Checkley W, Robinson CL, Baumann LM, Hansel NN, Romero K, Pollard SL, et al. 25-hydroxy vitamin D levels are associated with childhood asthma in a population-based study in Peru. Clin Exp Allergy. 2014. doi:10.1111/cea.12311.

3. Awasthi S, Vikram K. Serum 25 hydroxy vitamin D insufficiency associated with bronchial asthma in Lucknow, India. Indian J Pediatr. 2014;81:644-9.

4. Brown SD, Calvert HH, Fitzpatrick AM. Vitamin D and asthma. Dermatoendocrinol. 2012;4:137-45.

5. Chawes BL, Bønnelykke K, Jensen PF, Schoos AM, Heickendorff L, Bisgaard H. Cord blood 25(OH)-vitamin D deficiency and childhood asthma, allergy and eczema: the COPSAC2000 birth cohort study. PLoS One. 2014;9:e99856. 